\title{
Application Research on Teaching Model of College Flipped Classroom Based on SPOC
}

\author{
Hongyan Li \\ Changsha Medical University, Hunan, 410219, China
}

Keywords: SPOC flipped classroom; education model; college course teaching; application

\begin{abstract}
SPOC flipped classroom teaching is the miniaturization of the traditional massive open online course (MOOC). It is mainly faced with groups with learning foundation and learning ability. SPOC flipped classroom uses network teaching platform and carries out the design and development of online course teaching resources, including teaching contents, teaching strategies, learning and evaluation. This paper discusses the application research on the teaching model of college flipped classroom based on SPOC, and analyzes the development condition of SPOC flipped classroom to provide the SPOC teaching design of college courses. .
\end{abstract}

\section{Introduction}

Introduction: with the increasing development of teaching revolution in college courses, online teaching of the Internet becomes the mainstream. Compare with the traditional MOOC (massive open online course), SPOC online course has higher limitation and grade. It combines with flipped classroom, online learning, blended learning and other various learning models. Then, the reform and innovation of traditional course teaching is completed. Application of SPOC teaching model create new development method to college course revolution, which can promote the teaching quality.

\section{Analysis of SPOC Flipped Classroom Teaching and MOOC Teaching}

\subsection{Definition and main characteristics of SPOC flipped classroom teaching.}

SPOC flipped classroom teaching is one kind of teaching model with small scales, which realize the teaching content through the combination of the online teaching and course teaching. Therefore, SPOC flipped classroom teaching emphasizes the students' autonomy, and its biggest feature is the reversal of traditional teaching links. Students need to preview the contents Before the SPOC teaching. Teachers will help students to understand the class contents online, complete the homework and finish the teaching assessment. In Harvard University, Peking University, Tsinghua University, and Zhejiang University, they all use online course platform and open special online teaching with small scales. The university MOOC platforms have SPOC zone, students can access it and select the favorite or necessary course. They can watch the teaching, answering, homework and other contents. At present, Zhejiang University has SPOC flipped classroom teaching, which include flipped classroom, case teaching, discuss and learning. Moreover, the platform supports teaching resources communication and sharing among different courses.

\subsection{Relevance between SPOC flipped classroom teaching and MOOC teaching.}

The MOOC teaching is based on the Internet online platform. Open, low threshold, and non-compulsory teaching settings can attract college students and social groups to join. However, the user setting is too open, which will weak the course pertinence with free teaching content, teaching staff management and study effect. Most students will give up halfway. The similar SPOC flipped classroom teaching has massive teaching resources with professional and private course setting. Professional means the flipped classroom has limitation on the number of people with less than 500 people in the small scale online class. Moreover, study basement and learning ability is 
also the requirement. Private means the SPOC is strong in the personal character. The online platform will provide suitable learning content based on the practical situation and the student can subscribe to the interested courses. Therefore, SPOC and MOOC has similarity in teaching platform, content, and open. On the contrary, they have great differences in teaching staff requirement, teaching model design, classroom discussion, and learning assessment. SPOC teaching can integrate the advantages of online teaching and classroom teaching that will promote the teaching quality.

\section{Application of Flipped Class Model during College Teaching}

The main problems of college course teaching is the course teaching content and teaching form are too old, and the teacher has not enough supervision and management of the students' course study. The low learning autonomy is caused by the simple teaching content with poor diversified forms of teaching. Therefore, bring SPOC flipped class model, in one hand, we can adjust the learning initiative of the students by bring diversified teaching content and form. On the other hand, the small online discussion and learning assessment can supervise students with better assessment of learning result. SPOC flipped class model is the rebuilt for the original teaching content, teaching form and teaching supervision by the Internet. It has important function to the revolution of college teaching.

\subsection{Application of flipped class model during college teaching content establishment.}

In college courses, there is a large knowledge system with more teaching contents and knowledge points. Therefore, in the college courses construction of the teaching content, the construction of teaching objectives and teaching contents should be completed according to the students' learning situation and learning needs. Through the SPOC online teaching platform, teachers can help students prepare for the teaching content. Then, introduce the basic knowledge of the course, practical cases, etc., and make further exploration and analysis on the emphasis and difficult points in the teaching. With the help of small online teaching, we can complete the classroom teaching knowledge system construction. The college classroom construction of teaching system mainly includes the conceptual, theoretical and logical teaching contents, as well as the summary and division of the teaching contents in the classroom.

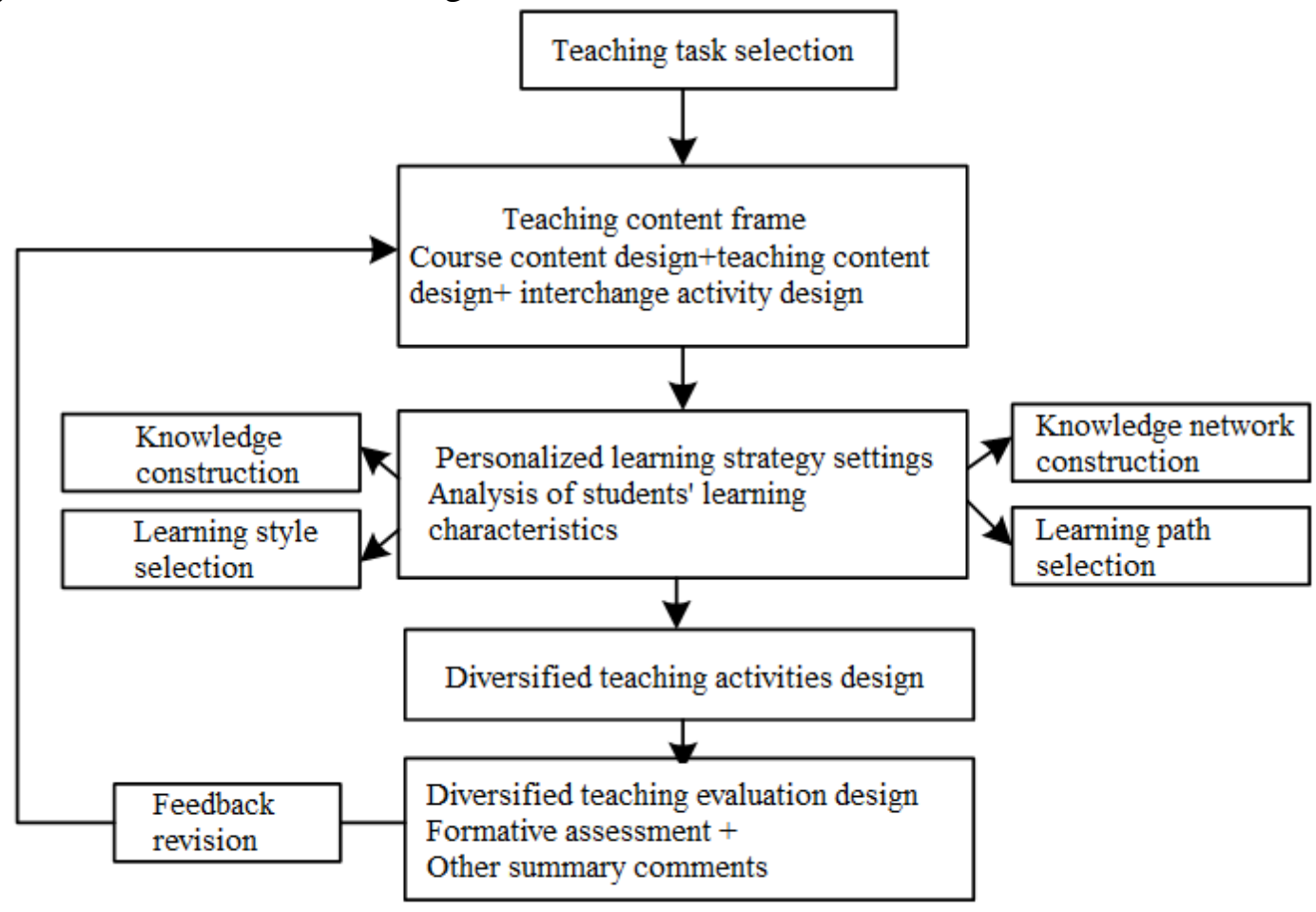

Fig.1 Model frame of SPOC flipped class model

During the teaching content establishment of SPOC class model, teachers mainly focus on 
students' learning experience and cognition. Through the organization of heuristic, exploratory and summary teaching content to effectively improve students' learning enthusiasm and cultivate students' good study habits. Therefore, SPOC classroom teaching has strong structural and pertinence, focus on knowledge fragmentation to realize whole knowledge system construction through short video. Finally, in the construction of college teaching content exchange and interaction, students and teachers mainly through Weibo, WeChat and other forms to realize the interaction. Figure 1 has the details.

\subsection{Application of flipped class model during college teaching strategy design.}

Only by building a scientific learning strategy can college students complete the required learning tasks in a limited time. We bring SPOC class model during the teaching strategy design can help students adjust their learning motivation, learning style and learning time, and complete the control and management of learning progress. In each class, teachers only focus on a small number of knowledge points, and the teaching content is explained and analyzed. The whole teaching process is controlled in about 10 minutes. Students can learn the knowledge according to their own situation, choose their learning content and learning progress. Moreover, they can in any time, at any place to watch the teaching video, so as to grasp the learning content, learning methods and learning path independently. The SPOC class model can complete the integration of various network teaching resources, and effectively connect the teaching theory with practice, so as to construct a complete knowledge network and teaching network. This application is beneficial to the choice and design of college students' learning strategies.

\subsection{Application of flipped class model during college teaching model.}

In college teaching, teaching method organization decides the effect of teacher's teaching and student's learning. Through SPOC class model can realize various teaching method organization. At first, bring links in teaching activities. Teachers can guide students with question and stimulate students' enthusiasm for learning and participation. After that, divide the teaching content into several related chapters. Each SPOC class only cover the key points of a particular chapter (controlled within 10 minutes). Then, according to the difficulty of the teaching content, all students are divided into different groups to discuss the topic through online interactive software such as video communication, online q\&a, project summary and other links. Otherwise, we can design the choice question or completion to help teachers to understand students' learning condition in the page of q\&a. At last, by setting up teaching methods such as exercises and important points, we can strengthen and deepen teaching knowledge points to cultivate students' ability of self-exploration and interactive communication. Through SPOC, we can realize the internalization and deepening of teaching knowledge, which can improve the teaching quality.

\subsection{Application of flipped class model during college teaching assessment.}

We need to obtain the teaching and learning condition through relevant assessment and analysis. SPOC can get correct analysis on teacher's teaching and students"' learning. We mainly use big data for teaching and learning analysis, which include such as teaching process assessment, online test analysis, classroom performance assessment, homework assessment and so on. These data can be obtained from the activities of teachers and learners. Based on the SPOC, we can obtain the condition of teaching and learning as well as manage the students' learning activities through the teaching assessment.

\section{Summary}

As the upgrade of the MOOC online teaching, the flipped classroom of SPOC aims at internal students and college students, which conduct online course teaching activities. Based on the Internet, the SPOC teaching can complete transformation and communication of the teaching information during the short Internet teaching with various teaching content, diversified teaching patterns, and standard teaching assessment. Therefore, SPOC flipped classroom will realize the integration and 
management of the Internet teaching resources. Moreover, it will effectively improve students' self-study ability and the quality of course teaching.

\section{References}

[1] From MOOC to SPOC: Lessons from MOOC at Tsinghua and UC Berkeley [J] Xu Wei, David Patterson. Modern Distance Education Research. 2014(04):56-57

[2] The Innovation Research of MOOC from the Perspective of Blended Learning: Case Study of SPOC [J]. Luo Jiutong, Sun Meng, Gu Xiaoqing. Modern Educational Technology. 2014(07):86-88

[3] Where to Go: Domestic Hotspots Research of MOOC Based on the Knowledge Map Analysis [J]. Wang Youmei, Ye Aimin, Lai Wenhua. China Educational Technology. 2015(07):102-103

[4] Research on Model to Balance Educational Resources Combining Flipped Classroom and MOOC [J]. Jiang Yanling, Guo Rong, Fu Tingting. China Educational Technology. 2015(04): $12-14$ 